\title{
Radical chain reactions involving 9-alkyl-9-borafluorenes
}

\author{
Ioulia Gorokhovik, Samuel Rieder, Guillaume Povie, and Philippe Renaud* \\ Department of Chemistry and Biochemistry, University of Bern, \\ Freiestrasse 3, 3012 Bern, Switzerland \\ E-mail: philippe.renaud@dcb.unibe.ch
}

Dedicated to Prof. Pierre Vogel on the occasion of his $70^{\text {th }}$ birthday

\begin{abstract}
The preparation of 9-alkyl-9-borafluorenes and their use as radical precursors in chain reactions were investigated. These organoboranes were found to be excellent precursors of primary and secondary alkyl radicals. Reactions were readily initiated by traces of oxygen and efficient processes involving sulfonyl-based radical traps were discovered. Due to the very high reactivity of the intermediate 9- $H$ and 9-alkyl-9-borafluorenes, problems of reproducibility were identified.
\end{abstract}

Keywords: Radical reaction, Lewis acidity, hydroboration, sulfurization, thiosulfonates, sulfones, sulfonyl chloride

\section{Introduction}

Nowadays, radical reactions represent a very useful tool in organic synthesis. ${ }^{1}$ Efficient and environmentally friendly ways to generate carbon-centered radicals remain a challenging problem faced by organic chemists. Organoboranes are privileged precursors for the generation of alkyl radicals ${ }^{2,3}$ via homolytic substitution $\left(\mathrm{S}_{\mathrm{H}}\right)$ by heteroatom-centered radicals. ${ }^{4}$ Radical chain reactions involving organoboranes have been intensively investigated., ${ }^{2,3,5,6}$ Initiation is usually performed by molecular oxygen, di-tert-butylperoxide or di-tert-butylhyponitrite. The use of benzenesulfonyl-containing radical trap $\left(\mathrm{PhSO}_{2} \mathrm{X}\right)$ led to efficient chain processes with a variety of alkyboron derivatives such as alkylcatecholboranes. ${ }^{6,8}$ The chain is propagated by the transient benzenesulfonyl radical $\mathrm{PhSO}_{2}$ (Scheme 1, eq. 1). Recently, Scaiano reported a theoretical investigation on the substitution reaction involving oxygen-centered radicals and trialkyl-/triarylboranes. ${ }^{9}$ The reaction mechanism involves an initial nucleophilic attack of the oxygen lone pair on the empty p orbital at boron and is best described as a nucleohomolytic reaction that shares many characteristics with conventional nucleophilic substitution (Scheme 1, 
eq. 2). Based on this report, it is expected that the Lewis acidity of the organoborane may play an important role in the process leading to homolytic substitution.

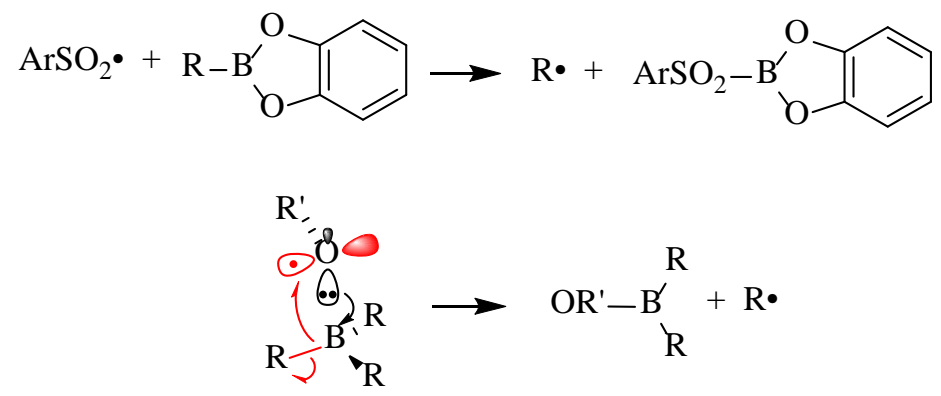

Scheme 1. Nucleohomolytic reaction at boron.

9-Alkyl-9-borafluorenes represent a fascinating class of organoboranes due to the $4 \pi$ antiaromatic nature of the central borole ring since the vacant p-orbital at boron is conjugated with the $\pi$-system. Interactions with a Lewis base breaks the planarity, removing the p-orbital from the conjugation. ${ }^{10}$ Therefore, 9-borafluorenes are strong Lewis acids and highly reactive. They were first synthesized by Köster and Benedikt in $1963^{11,12}$ and by Narula and Nöth in $1985,{ }^{13}$ but the most efficient synthesis was developed only recently by Holthausen, Wagner and coworkers (Scheme 2). ${ }^{14,15,16}$ 2,2'-Dibromobiphenyl 1 underwent double lithium-bromine exchange, followed by lithium-boron exchange ${ }^{15}$ delivering desired 9-chloro-9-borafluorene 2. Then, 9- $\mathrm{H}$-9-borafluorene $\mathbf{3}$ could be generated by reduction of 9-chloro-9-borafluorene 2 or 9bromo-9-borafluorene in the presence of triethylsilane in benzene. ${ }^{16}$ Borane 3 is particularly unstable due to its antiaromatic character and it tends to reversibly form a dimer and to rapidly degrade, affording isomers and oligomers that exclude boron's empty p-orbital from the $\pi$ plane. ${ }^{14,16,17,18}$ The mechanisms of isomerization and polymerization have been studied. ${ }^{16,17,18}$ Unsymmetrical borafluorenes, synthesized by boron insertion in $\mathrm{C}-\mathrm{H}^{19}$ and $\mathrm{C}-\mathrm{C}^{20}$ bonds, and fluorinated 9-borafluorenes $^{21}$ were also studied.

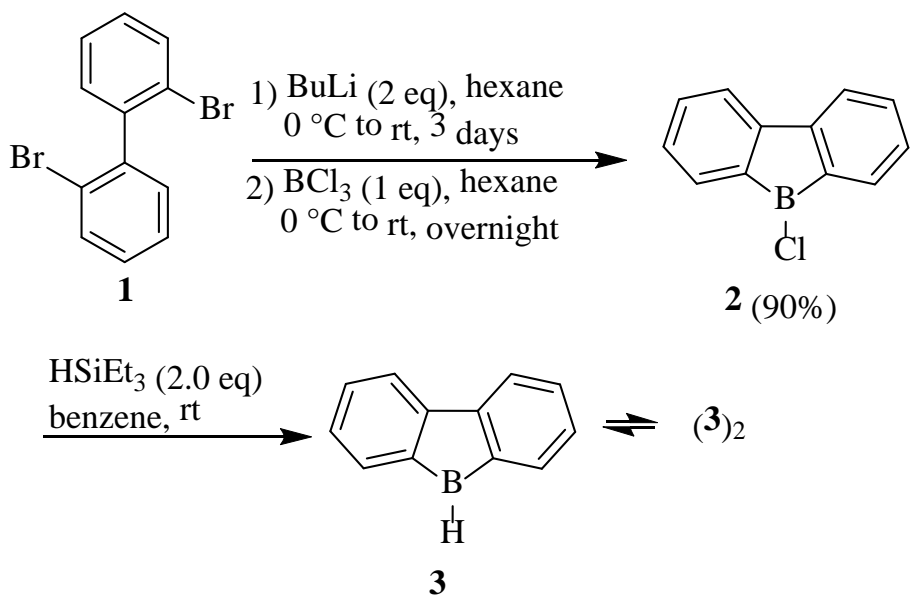

Scheme 2. Reported synthesis of 9-alkyl-9-borafluorenes. 
When 9-H-9-borafluorene 3 was placed in the presence of ethylene, hydroboration was observed. ${ }^{14}$ In the case of a terminal alkyne, mono or double hydroboration were observed. ${ }^{16}$ To circumvent the stability problem of compound 3, pyridine ${ }^{16}$ and dimethylsulfide ${ }^{18}$ stabilized $^{2}$ complexes of the 9 - $\mathrm{H}$-9-borafluorene 3 were prepared from 9-chloro-9-borafluorene $\mathbf{2}$ in nearly quantitative yield. The complex $\mathbf{3} \cdot \mathrm{SMe}_{2}$ was claimed to be a storable adduct of the reagent $\mathbf{3}$ (it does not oligomerize) and could be directly used for the hydroboration of alkynes (Scheme 3). These hydroborations led to 9-alkyl and 9-alkenyl-9-borafluorenes 4 and 5. After hydroboration, $\mathrm{Me}_{2} \mathrm{~S}$ could be removed by storing the compound for several days under dynamic vacuum.

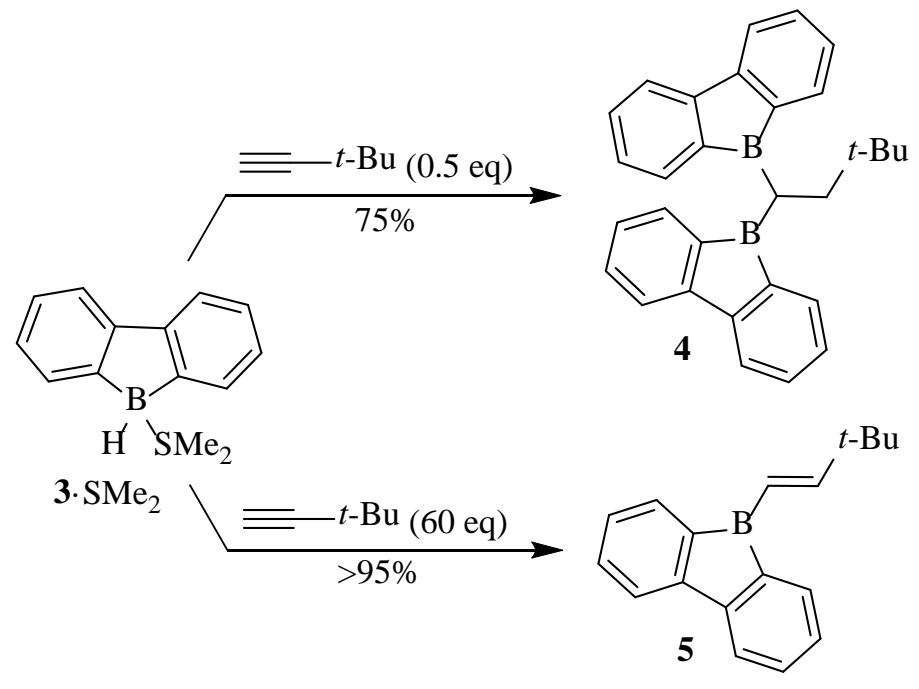

Scheme 3. Hydroboration with 9-H-9-borafluorene-dimethylsulfide complex $3 \cdot \mathrm{SMe}_{2}$.

Due to their exceptional Lewis acidity, 9-alkyl-9-borafluorenes are expected to be highly reactive radical precursors that deliver selectively alkyl radicals due to their greater stability over aryl radicals. This hypothesis is nicely supported by the report of Chung who patented the use of 9-octylperoxy-9-borafluorene, generated by reaction of 9-octyl-9-borafluorene with oxygen, as an initiator for radical living polymerization processes. $^{22}$ In connection with our interest in organoboranes and their use as radical precursors, ${ }^{5,23,24}$ we decided to synthesize and investigate the use of 9-alkyl-9-borafluorenes in radical reactions. We report herein that these compounds readily afford alkyl radicals that can be trapped successfully. The scope and limitations of this approach are presented.

\section{Results and Discussion}

Preparation of the 9-H-9-borafluorene. The first part of our study consisted in optimizing the protocol to prepare the desired reagent 9-chloro-9-borafluorene 2. The literature procedure (Scheme 2) requires about 4 days $^{15}$ and was giving very variable results. We observed that the 
second lithium-bromine exchange (conversion of $\mathbf{1}$ to 2 ) is particularly slow in hexane. In ether solvents (THF or $\mathrm{Et}_{2} \mathrm{O}$ ) both exchanges could take place effectively in 3 hours, but remaining traces of the solvent hampered further reaction with boron trichloride, possibly by forming complexes with boron or organolithium species. To avoid these problems, the lithium-bromine exchange reaction on 2,2'-dibromobiphenyl $\mathbf{1}$ was performed in refluxing toluene. ${ }^{25}$ After one hour, the double exchange reaction was complete. Boron trichloride was directly added to the dilithiated biphenyl and the reaction mixture was stirred overnight at room temperature (Scheme 4). After distillation, the chloroborane 2 was obtained in $77 \%$ yield and the physical and spectroscopic properties of $\mathbf{2}$ are in accordance with literature data. ${ }^{15}$ Even if the reduction of $\mathbf{2}$ to the borane $\mathbf{3}$ works well on the crude chloride, we found that distillation of $\mathbf{2}$ enhanced the reproducibility of the whole procedure. By this procedure, 3 was prepared on $500 \mathrm{mg}$ scale within 24 hours when it took about 4 days using the literature procedure. ${ }^{15}$

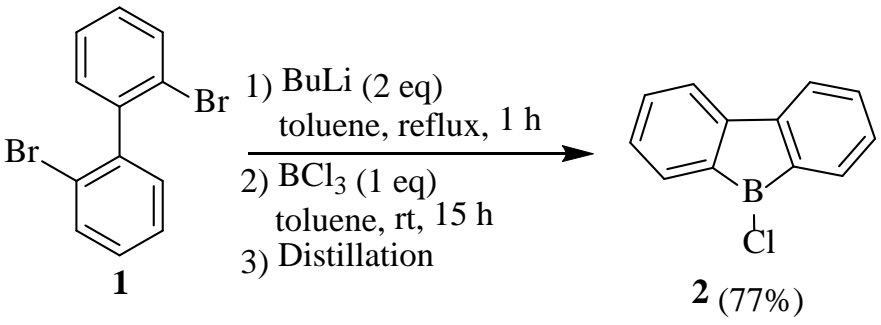

Scheme 4. Optimized synthesis of 9-chloro-9-borafluorene.

Generation of radicals. Reduction of 9-chloro-9-borafluorene 2 to 9-H-9-borafluorene 3 was performed in benzene according to literature procedure. ${ }^{16}$ As reported, this compound is not stable and polymerizes rapidly. ${ }^{16}$ Therefore, 3 was used immediately and was neither isolated nor stored. 9- $H$-9-borafluorene $\mathbf{3}$ was tested for the hydroboration of cyclohexene $\mathbf{6 a}$. The reaction was simply performed by adding the alkene to the previous reaction mixture (Scheme 5). After two hours at room temperature, $S$-phenyl benzenethiosulfonate $\left(\mathrm{PhSO}_{2} \mathrm{SPh}\right)$ was added. The reaction was allowed to react for $20 \mathrm{~h}$ at room temperature and afforded the desired cyclohexyl phenyl sulfide $\mathbf{8 a} .^{24}$ The reaction was presumably initiated by traces of oxygen present in the solvent. Addition of a radical initiator like di-tert-butylhyponitrite did not change significantly the reaction outcome. The whole sequence was performed as a one-pot procedure and provided 8a in essentially quantitative yield. Attempts to use other solvents such as hexane, dichloromethane, diethyl ether were unsuccessful. In toluene, the yield for the formation of $\mathbf{8 a}$ was noticeably lower (below 20\%). 

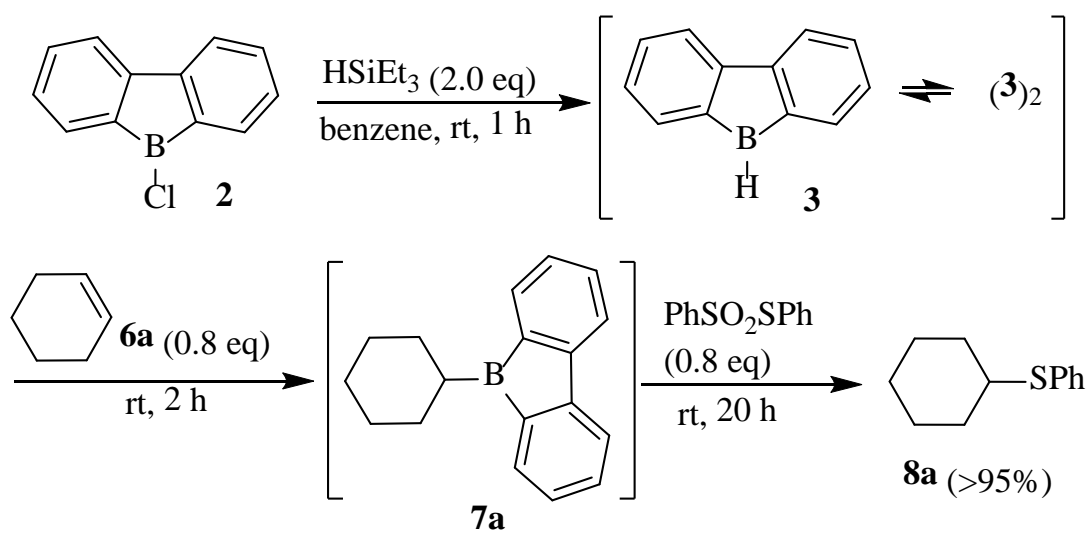

Scheme 5. Hydroboration-radical sulfurization of cyclohexene $\mathbf{6 a}$.

The scope of the sulfurization reaction was examined with different alkenes (Scheme 6). Primary radicals generated from 4-(phenyl)methylenecyclohexane $\mathbf{6 b}$ and $\beta$-(-)-pinene 6c provided the desired sulfides $\mathbf{8 b}$ and $\mathbf{8 c}$ in $89 \%$ and $21 \%$ yield, respectively. The secondary radical generated from $\alpha-(-)$-pinene $\mathbf{6 d}$ afforded $\mathbf{8 d}$ in $63 \%$ yield. As anticipated, for the two pinenes 6c and 6d, hydroboration occurred preferentially from the least hindered face. The sulfides 8c and $\mathbf{8 d}$ were obtained as single diastereomers demonstrating that the hydroboration and the radical reaction (for 8d) are fully diastereoselective. For compound $\mathbf{8 b}$, a $4: 5$ diastereomeric ratio was obtained. When a mixture of the two pinenes $\mathbf{6 c}$ and $\mathbf{6 d}$ (2 equivalents of each relative to borane 3 ) was used, only the compound $\mathbf{8 c}$ coming from the hydroboration of the terminal alkene $\beta$-(-)-pinene $\mathbf{6 c}$ was observed demonstrating that despite its high reactivity, borane 3 reacts with the same chemoselectivity as classical hydroborating agents such as $\mathrm{BH}_{3}$ and dialkyboranes.
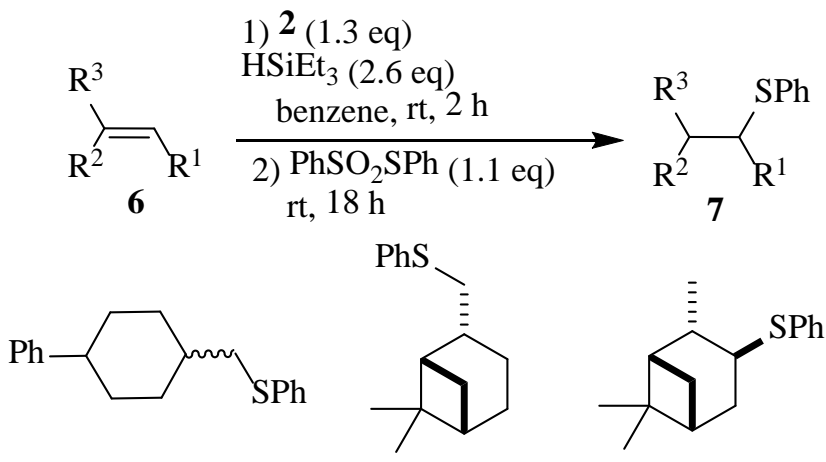

$$
\mathbf{8 b}(\mathrm{dr} 4: 5,89 \%) \quad \mathbf{8 c}(21 \%) \quad \mathbf{8 d}(63 \%)
$$

Scheme 6. Hydroboration-radical sulfurization of alkenes.

The use of radical traps was tested next starting from 4-(phenyl)methylenecyclohexane $\mathbf{6 b}$. The chlorination reaction with benzenesulfonyl chloride ${ }^{24}$ afforded $\mathbf{9 b}$ in $94 \%$ yield (Scheme 7 , 
eq. 3). Allylation with ethyl 2-((phenylsulfonyl)methyl)acrylate ${ }^{8}$ was also investigated. Despite the use of 1.6 equivalents of the trap and initiation by di-tert-butyl hyponitrite at $45^{\circ} \mathrm{C}$, the yield for the formation of allylated compound 10b remained modest (Scheme 7, eq. 4). Other radical traps such as phenyl phenylethynyl sulfone ${ }^{23}$ and cyclohexenenone ${ }^{26}$ were also tested but did not provide the desired products.

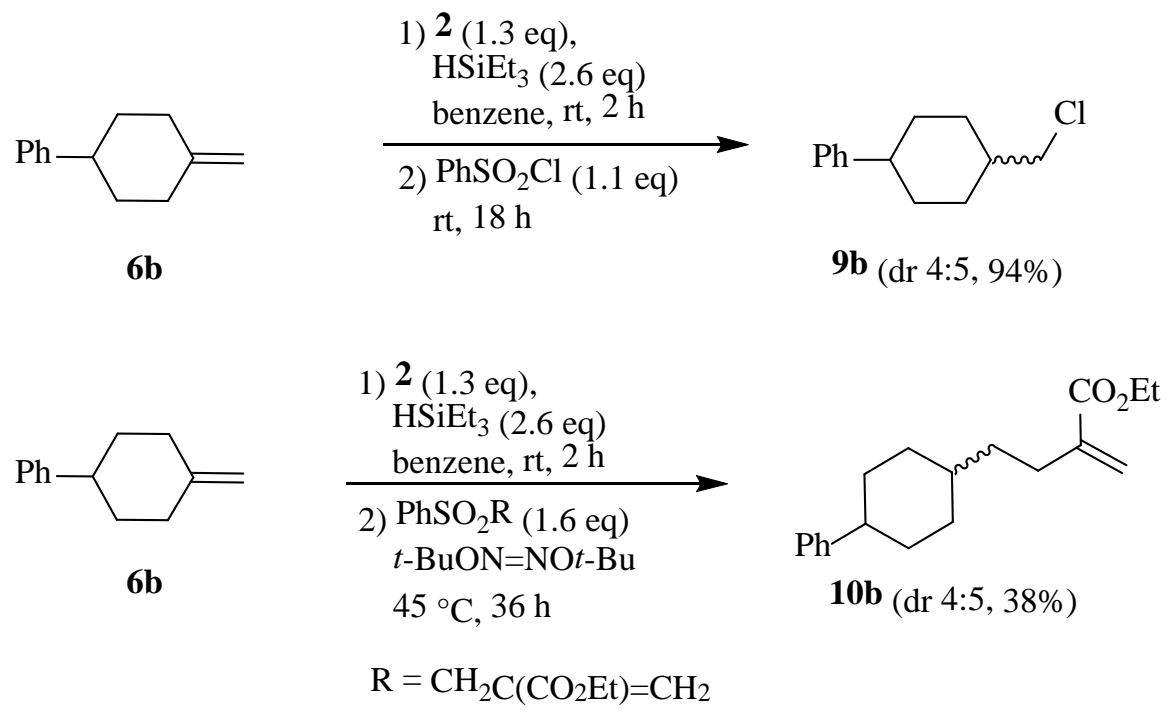

Scheme 7. Hydroboration-radical chlorination and allylation of alkenes.

Reproducibility of the results. The reactions reported here were shown to be difficult to reproduce. All reactions were repeated several times and significant variations of conversion and yield were observed. All our efforts to identify the factors responsible for these variations were inconclusive. However, experimental observations indicate that the problem is related to the formation of the 9-alkyl-9-borafluorene and not to the radical reaction. Indeed, oxidative treatment of the organoborane $\mathbf{7 b}$ obtained by hydroboration of $\mathbf{6 b}$ with freshly distilled 9chloro-9-borafluorene 3 was investigated (Scheme 8). The alcohol 11b was obtained in only 45\% yield together with $42 \%$ of starting alkene $\mathbf{6 b}$. The possibility of a reversible hydroboration step was investigated but could not be clearly demonstrated. The same batch of $\mathbf{7 b}$ afforded the sulfide $\mathbf{8 b}$ in 30-45\% yield upon reaction with $\mathrm{PhSO}_{2} \mathrm{SPh}$ (the reaction was repeated 3-4 times). 


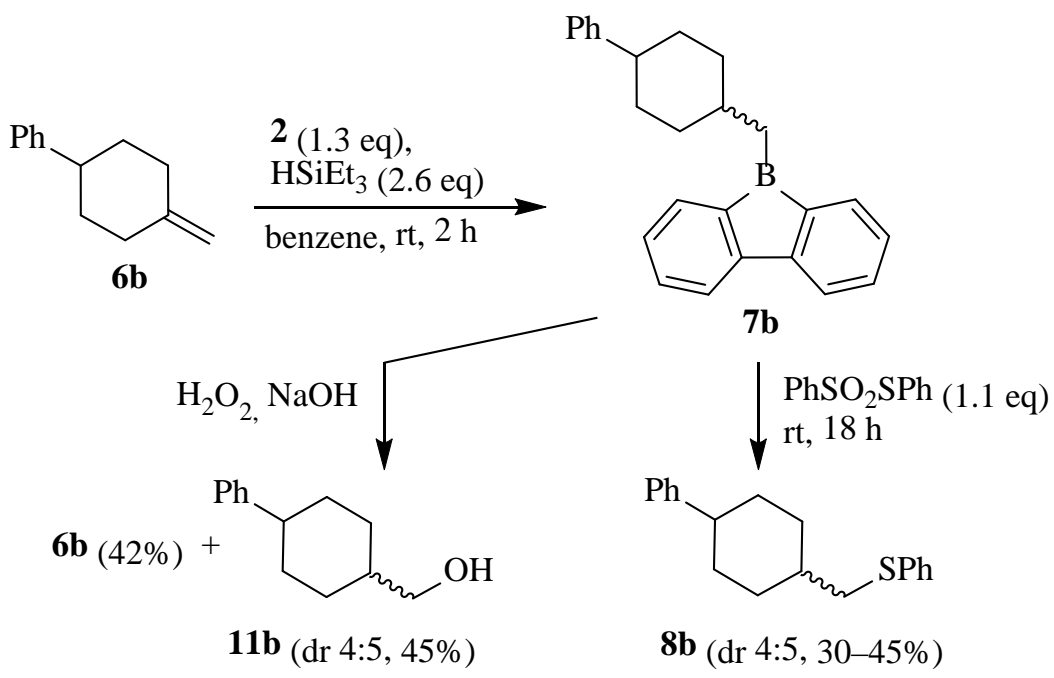

Scheme 8. Hydroboration-oxidation/sulfurization of 4-(phenyl)methylenecyclohexane $\mathbf{6 b}$.

\section{Conclusions}

9-Alkyl-9-borafluorenes have been shown to be extremely valuable radical precursors. The reactivity of these compounds is such that residual traces of oxygen in the solvent are sufficient to initiate efficient radical chain reactions involving phenylsulfonyl radicals. Primary and secondary alkyl radicals could be generated and trapped using benzenesulfonyl based radical traps. Despite this proof of concept, the high instability of 9- $H$ - and 9-alkyl-9-borafluorenes limits the reproducibility of the method. A more reliable procedure involving stabilization of the borane 3 and the alkylborane intermediate 7 by complexation with Lewis base such as dimethyl sulfide is currently under investigation.

\section{Experimental Section}

General. All reactions were performed in heat-gun dried or oven dried glassware, under nitrogen or argon atmosphere, using schlenk technique. Solvents were filtered over anhydrous alumina columns under a positive pressure of argon. Extraction and purification solvents were technical grade, and were distilled prior to use. Commercial reagents were used without prior purification. 2,2'-dibromobiphenyl was synthesized using a known procedure ${ }^{27}$. Flash column chromatography was performed using Silicycle silica 60 (230-400 mesh). Filtration was performed using aluminium oxide (AlOx), 507-C-I Neutral. Thin layer chromatography (TLC) was performed using Silicycle glass backed silica gel $60 \mathrm{~F}_{254}$ plates, and vizualisation was achieved with UV irradiation (254 nm) or using $\mathrm{KMnO}_{4}$ stain. Gas chromatography (GC) was performed on a Thermo Electron instrument Trace GC Ultra fitted with a Macherey-Nagel 


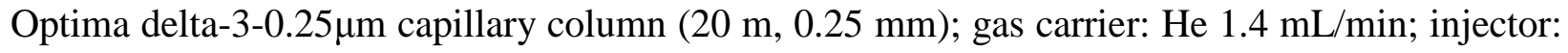
$220^{\circ} \mathrm{C}$ split mode; detector: FID $280^{\circ} \mathrm{C}, \mathrm{H}_{2} 35 \mathrm{~mL} / \mathrm{min}$, air $350 \mathrm{~mL} / \mathrm{min}$. Method : Starting from $50^{\circ} \mathrm{C}$ for 1 minute, the temperature was increased to $180^{\circ} \mathrm{C}$ at $8{ }^{\circ} \mathrm{C} / \mathrm{min}$, then to $280^{\circ} \mathrm{C}$ at 40 ${ }^{\circ} \mathrm{C} / \mathrm{min}$. Gas chromatography - mass spectroscopy (GCMS) were performed on a Finnigan Trace GC/MS (quadrupole mass analyzer using electron impact $70 \mathrm{eV}$ ), fitted with a MachereyNagel Optima delta-3-0.25 $\mu \mathrm{m}$ capillary column $(20 \mathrm{~m}, 0.25 \mathrm{~mm})$; gas carrier: He $1.2 \mathrm{~mL} / \mathrm{min}$; injector: $220^{\circ} \mathrm{C}$ split mode, using the same method. Proton NMR ( ${ }^{1} \mathrm{H}$ NMR) and carbon NMR $\left({ }^{13} \mathrm{C}\right.$ NMR) spectra were recorded on a Brüker Avance 300 or Brüker Avance II 400 spectrometers $\left({ }^{1} \mathrm{H}\right.$ frequency at 300.18 or $400.13 \mathrm{MHz},{ }^{13} \mathrm{C}$ frequency at 75.48 or $100.62 \mathrm{MHz}$ ) at room temperature (rt). Boron NMR $\left({ }^{11} \mathrm{~B}\right.$ NMR) was recorded on a Bruker Avance II 400 spectrometer $\left({ }^{11} \mathrm{~B}\right.$ frequency at $\left.128.38 \mathrm{MHz}\right)$ at room temperature. Chemical shifts $(\delta)$ are reported in parts per million (ppm) relative to residual proton signals in $\mathrm{CDCl}_{3}(\delta$ 7.26, 77.16 $\mathrm{ppm})$ or $\mathrm{C}_{6} \mathrm{D}_{6}(\delta 7.16,128.06 \mathrm{ppm})$ for ${ }^{1} \mathrm{H}$ and ${ }^{13} \mathrm{C}$, and to $\mathrm{Et}_{2} \mathrm{OBF}_{3}$ as an external standard $(\delta 0$ ppm) for ${ }^{11} \mathrm{~B}$ NMR. Coupling constants $(J)$ are reported in Hertz $(\mathrm{Hz})$ and refer to apparent multiplicities. The following abbreviations are used for the multiplicities: s: singlet, brs: broad singlet, d: doublet, t: triplet, q: quartet and m: multiplet). Infrared spectra (IR) were recorded on a Jasco FT-IR-460 Plus spectrometer equipped with a Specac MKII Golden Gate Single Reflection Diamond ATR System. The characteristic IR absorption frequencies are reported in wave numbers $\left(\mathrm{cm}^{-1}\right)$. Low resolution mass spectroscopy (MS) was obtained from the GCMS. Highresolution mass spectra (HRMS) were performed on a Thermo Scientific LTQ Orbitrap XL mass S-3 spectrometer using ESI mode at the University of Bern or on a Thermo DFS double-focusing magnetic sector mass spectrometer using EI mode at $45 \mathrm{eV}$ at the University of Zürich.

9-Chloro-9-borafluorene (2). ${ }^{15}$ To a solution of 2,2'-dibromobiphenyl (900 mg, $2.9 \mathrm{mmol}$ ) in toluene $(20 \mathrm{~mL})$ was added at room temperature a $2.5 \mathrm{M}$ solution of $n \mathrm{BuLi}$ in hexane $(2.3 \mathrm{~mL}$, $5.8 \mathrm{mmol}$ ). The reaction mixture was refluxed for $1 \mathrm{~h}$, and was followed by performing GCMS on hydrolyzed aliquots of the reaction to monitor the disappearance of 2,2'-dibromobiphenl and 2bromobiphenyl and the appearance of biphenyl. The progressive appearance of a white precipitate was observed. The reaction mixture was then cooled to $0{ }^{\circ} \mathrm{C}$, and a $1 \mathrm{M}$ solution of $\mathrm{BCl}_{3}$ in heptane $(2.9 \mathrm{~mL}, 2.9 \mathrm{mmol})$ was added. The suspension turned yellow, and was stirred at room temperature for $15 \mathrm{~h}$. The suspension was decanted, and salts were separated from the liquid, rinced twice with dry toluene $(5 \mathrm{~mL})$ and discarded. Toluene was removed from the filtrate by distillation at $45^{\circ} \mathrm{C}$ and 65 mbar. A bright yellow oil was obtained. It could be distilled to afford a bright yellow oil ${ }^{15}$ (439 mg, 77\%), or could be used without prior purification. ${ }^{1} \mathrm{H}$ NMR analyses differs slightly from the literature, as we used $\mathrm{C}_{6} \mathrm{D}_{6}$ instead of chlorinated solvents, the other analyses matched literature data. ${ }^{15} \mathrm{H}$ NMR $\left(\mathrm{C}_{6} \mathrm{D}_{6}, 300 \mathrm{MHz}\right): \delta 7.60(\mathrm{~d}, J 7.0$ $\mathrm{Hz}, 2 \mathrm{H}), 7.36-7.33$ (m, 2H), 7.17-7.11 (m, 2H), 7.01-6.94 (m, 2H). ${ }^{13} \mathrm{C}$ NMR $\left(\mathrm{C}_{6} \mathrm{D}_{6}, 75 \mathrm{MHz}\right): \delta$ 153.5, 135.3, 133.0, 128.8, 120.0. The carbon directly attached to boron was not detected. ${ }^{11} \mathrm{~B}$ NMR ( $\left.\mathrm{C}_{6} \mathrm{D}_{6}, 128 \mathrm{MHz}\right): \delta 63.6(\mathrm{~s})$. 
General Procedure. 9-Chloro-9-borafluorene (100 mg, $0.48 \mathrm{mmol}$ ) was dissolved in benzene (1 $\mathrm{mL})$ and triethylsilane $(0.15 \mathrm{~mL}, 0.96 \mathrm{mmol})$ was added. The reaction mixture was stirred at room temperature for $1 \mathrm{~h}$. The alkene was then added $(0.37 \mathrm{mmol})$ in benzene $(1 \mathrm{~mL})$, and the reaction mixture was further stirred for $2 \mathrm{~h}$. The trap $(0.4 \mathrm{mmol})$ was then added, the reaction mixture was stirred at room temperature for $18-20 \mathrm{~h}$ and filtered through aluminium oxide. The pad of aluminium oxide was rinsed with diethylether, and the solvents were removed under reduced pressure. The crude material was purified by silica gel column chromatography using pure pentane as the eluent and afforded the desired compound.

Cyclohexyl(phenyl)sulfane (8a). ${ }^{28}$ Prepared according to general procedure. The title compound was obtained as a colorless oil (71 mg, quantitative yield). Analyses matched literature data ${ }^{28}$. ${ }^{1} \mathrm{H}$ NMR $\left(\mathrm{CDCl}_{3}, 300 \mathrm{MHz}\right): \delta$ 7.52-7.42 (m, 2H), 7.40-7.22 (m, 3H), 3.23-3.11 (m, 1H), 2.122.00 (m, 2H), 1.90-1.79 (m, 2H), 1.73-1.63 (m, 1H), 1.52-1.24 (m, 5H). MS (EI): m/z 192.2.

Phenyl((4-phenylcyclohexyl)methyl)sulfane (8b). Prepared according to general procedure. The title compound was obtained as a yellow oil. Obtained as a 4:5 mixture of diastereoisomers with traces of inseparable side product PhSSPh (92 mg, 89\%). ${ }^{1} \mathrm{H} \mathrm{NMR}\left(\mathrm{CDCl}_{3}, 300 \mathrm{MHz}\right)$ : $\delta$ 7.40-7.16 (m, 20H), 3.07 (d, $J 7.5 \mathrm{~Hz}, 2 \mathrm{H})$ and 2.90 (d, $J 6.8 \mathrm{~Hz}, 2 \mathrm{H}), 2.67-2.56(\mathrm{~m}, 1 \mathrm{H})$ and 2.50 (tt, $J$ 3.3, $12.1 \mathrm{~Hz}, 1 \mathrm{H}), 2.15-1.56(\mathrm{~m}, 14 \mathrm{H}), 1.48$ (dq, $J 3.3,12.8 \mathrm{~Hz}, 2 \mathrm{H})$ and 1.20 (dq, $J$ 3.3, $12.8 \mathrm{~Hz}, 2 \mathrm{H}) .{ }^{13} \mathrm{C} \mathrm{NMR}\left(\mathrm{CDCl}_{3}, 75 \mathrm{MHz}\right): \delta 147.4,147.1,137.6,137.2,129.1$ (2), 129.0 (4), 128.8 (2), 128.4 (4), 127.0 (2), 126.9 (2), 126.1, 126.0, 125.8, 125.7, 44.4, 43.4, 41.0, 37.4, 36.6, 34.0 (2), 33.2 (2), 32.7, 29.6 (2), 28.8 (2). IR: $v_{\max }$ 3023, 2920, 2849, 1584, 1479, 1447, 1437, 1024, 734, 697, 688. HRMS (ESI): $\mathrm{m} / \mathrm{z}$ calcd. for $[\mathrm{M}]^{+} \mathrm{C}_{19} \mathrm{H}_{22} \mathrm{~S}$ : 282.1437, found: 282.1442. ${ }^{29}$

((6,6-Dimethylbicyclo[3.1.1]heptan-2-yl)methyl)(phenyl)sulfane $\quad(8 \mathbf{c}) .^{30} \quad$ 9-Chloro-9borafluorene, (obtained from 2,2'-dibromobiphenyl (150 mg, $0.48 \mathrm{mmol}$ ) and used without prior purification) was dissolved in benzene $(1 \mathrm{~mL})$ and triethylsilane $(0.15 \mathrm{~mL}, 0.96 \mathrm{mmol})$ was added. The reaction mixture was stirred at room temperature for $1 \mathrm{~h}$. $\alpha$-pinene $(154 \mu \mathrm{L}, 0.96$ $\mathrm{mmol})$ and $\beta$-pinene (154 $\mu \mathrm{L}, 0.96 \mathrm{mmol})$ were then added, and the reaction mixture was further stirred for $2 \mathrm{~h}$. The trap $(0.48 \mathrm{mmol})$ was then added, the reaction mixture was stirred at room temperature for $24 \mathrm{~h}$ and filtered through aluminium oxide. The pad of aluminium oxide was rinsed with diethylether, and the solvents were removed under reduced pressure. The crude was purified by silica gel column chromatography using pentane as the eluent and afforded the desired compound as a colorless oil, with traces of inseparable side product ( $25 \mathrm{mg}, \mathbf{2 1 \%}$ ). ${ }^{1} \mathrm{H}$ NMR (CDCl $3,400 \mathrm{MHz}$ ): $\delta$ 7.35-7.24 (m, 4H), 7.21-7.13 (m, 1H), 3.06-2.91 (m, 2H), 2.39-2.19 (m, 2H), 2.11-1.81 (m, 5H), 1.65-1.56 (m, 1H), 1.20 (s, 3H), 1.04 (s, 3H), 0.89 (d, J 9.6 Hz, 1H). ${ }^{13} \mathrm{C} \mathrm{NMR}\left(\mathrm{CDCl}_{3}, 100 \mathrm{MHz}\right): \delta$ 137.3, 129.0 (2), 128.9 (2), 125.7, 45.8, 41.4, 41.0, 40.7, 38.8, 33.5, 28.1, 26.3, 23.4, 22.2. IR: $v_{\max } 3000-2700,1580,1477,1437,1024,735,687$. HRMS (ESI): $\mathrm{m} / \mathrm{z}$ calcd. for $[\mathrm{M}]^{+} \mathrm{C}_{16} \mathrm{H}_{22} \mathrm{~S}: 246.1437$, found: $246.1440 .{ }^{29}$ 
Phenyl(2,6,6-trimethylbicyclo[3.1.1]heptan-3-yl)sulfane (8d). ${ }^{31}$ Prepared according to general procedure. The title compound was obtained as a colorless oil (57 mg, 63\%). Analyses matched literature data ${ }^{31} .{ }^{1} \mathrm{H}$ NMR $\left(\mathrm{CDCl}_{3}, 300 \mathrm{MHz}\right): \delta$ 7.47-7.39 (m, 2H), 7.34-7.14 (m, 3H), 3.45-3.34 (m, 1H), 2.59-2.44 (m, 1H), 2.38-2.27 (m, 1H), 2.15-2.02 (m, 2H), 1.99-1.88 (m, 1H), 1.88-1.78 (m, 1H), 1.20 (s, 3H), 1.11 (d, J 7.1 Hz, 3H), 1.02 (s, 3H), 0.98 (d, J $9.5 \mathrm{~Hz}, 1 \mathrm{H}) . \mathrm{MS}$ (EI): m/z 246.3.

(4-(Chloromethyl)cyclohexyl)benzene (9b). Prepared according to general procedure. The title compound was obtained as a colorless oil, in a 4:5 mixture of diastereoisomers (72 mg, 94\%). ${ }^{1} \mathrm{H}$ NMR $\left(\mathrm{CDCl}_{3}, 300 \mathrm{MHz}\right): \delta$ 7.34-7.28 (m, 4H), 7.25-7.19 (m, 6H), $3.64(\mathrm{~d}, J 7.7 \mathrm{~Hz}, 2 \mathrm{H})$ and 3.46 (d, $J 6.3 \mathrm{~Hz}, 2 \mathrm{H}), 2.70-2.60(\mathrm{~m}, 1 \mathrm{H})$ and 2.50 (tt, $J 3.5,12.0 \mathrm{~Hz}, 1 \mathrm{H}), 2.11-1.93(\mathrm{~m}, 6 \mathrm{H})$, 1.91-1.82 (m, 2H), 1.80-1.66 (m, 6H), 1.51 (dq, J 3.4, $12.7 \mathrm{~Hz}, 2 \mathrm{H})$ and 1.22 (dq, J 3.6, $12.7 \mathrm{~Hz}$, 2H). ${ }^{13} \mathrm{C} \mathrm{NMR}\left(\mathrm{CDCl}_{3}, 75 \mathrm{MHz}\right): \delta$ 147.2, 146.8, 128.5 (4), 127.0 (2), 126.9 (2), 126.1, 126.1, 51.0, 47.5, 44.3, 43.1, 40.0, 36.2, 33.7 (2), 31.1 (2), 28.8 (2), 28.0 (2). IR: $v_{\max }$ 2923, 2853, 1491, 1449, 729, 697. HRMS (EI): $\mathrm{m} / \mathrm{z}$ calcd. for $[\mathrm{M}]^{+} \mathrm{C}_{13} \mathrm{H}_{17}{ }^{35} \mathrm{Cl}$ : 208.10133, found: 208.10130.

Ethyl 2-((4-phenylcyclohexyl)methyl)acrylate (10b). Prepared according to general procedure using ethyl 2-((phenylsulfonyl)methyl)acrylate $(150 \mathrm{mg}, 0.6 \mathrm{mmol})$ as a trap and di-tertbutylhyponitrite ( $7 \mathrm{mg}, 0.04 \mathrm{mmol}$ ) as an initiator. The reaction was then stirred at $45{ }^{\circ} \mathrm{C}$ for $36 \mathrm{~h}$. The title compound was obtained as a colorless oil in a 4:5 mixture of diastereoisomers (40 mg, 38\%). ${ }^{1} \mathrm{H}$ NMR (CDCl, $400 \mathrm{MHz}$ ): $\delta$ 7.33-7.14 (m, 10H), 6.15 (brs, 2H), 5.56-5.53 (m, 2H), 4.22 (q, J 7.0 Hz, 4H), 2.65-2.41 (m, 2H), 2.40-2.29 (m, 4H), 1.96-1.86 (m, 4H), 1.76-1.37 (m, $16 \mathrm{H}), 1.32$ (t, J 7.0 Hz, 6H), 1.17-1.02 (m, 2H). ${ }^{13} \mathrm{C} \mathrm{NMR}\left(\mathrm{CDCl}_{3}, 100 \mathrm{MHz}\right): \delta$ 167.8, 167.6, 147.8, 147.6, 141.6, 141.5, 128.4 (2), 128.4 (2), 127.1 (2), 127.0 (2), 126.0, 125.9, 124.3, 124.2, 60.7 (2), 44.7, 43.7, 37.2, 36.2, 34.4 (2), 33.6 (2), 32.9, 30.9, 30.4, 30.2 (2), 29.5, 29.0 (2) 14.4 (2). IR: 2921, 2852, 1715, 1631, 1492, 1450, 1189, 1150, 1028, 939, 752, 698. HRMS (ESI): $\mathrm{m} / \mathrm{z}$ calcd. for $[\mathrm{M}+\mathrm{H}]^{+} \mathrm{C}_{19} \mathrm{H}_{27} \mathrm{O}_{2}$ : 287.2006 , found: 287.2011.

(4-Phenylcyclohexyl)methanol (11b). 9-chloro-9-borafluorene (100 mg, $0.48 \mathrm{mmol}$ ) was dissolved in benzene $(1 \mathrm{~mL})$ and triethylsilane $(0.15 \mathrm{~mL}, 0.96 \mathrm{mmol})$ was added. The reaction mixture was stirred at room temperature for 1h. (4-methylenecyclohexyl)benzene was then added $(0.37 \mathrm{mmol})$, and the reaction mixture was further stirred for $2 \mathrm{~h}$. Then, ethanol $(0.4 \mathrm{~mL})$ was added and the reaction mixture was stirred at room temperature for 15 minutes. A sodium hydroxide solution (3M, $0.4 \mathrm{~mL}$ ) and hydrogen peroxide solution (30 wt\%, $0.4 \mathrm{~mL}$ ) were added and the reaction mixture was stirred at room temperature for $18 \mathrm{~h}$. Water and ethyl acetate were added and the layers were separated. The aqueous layer was extracted with ethyl acetate twice. The organic layers were combined, dried on $\mathrm{Na}_{2} \mathrm{SO}_{4}$, filtered and evaporated. The crude was purified by silica gel column chromatography using pentane to pentane /ethyl acetate $7 / 3$ as the eluent and afforded the desired compound as an off-white paste (30 $\mathrm{mg}, \mathbf{4 5 \%}$ ), along with starting alkene (25 mg, 42\%). The desired compound was obtained as a 4:5 mixture of 
diastereoisomers. ${ }^{1} \mathrm{H}$ NMR $\left(\mathrm{CDCl}_{3}, 300 \mathrm{MHz}\right): \delta$ 7.34-7.16 (m, 10H), $3.72(\mathrm{~d}, J 7.5 \mathrm{~Hz}, 2 \mathrm{H})$ and 3.52 (d, $J 6.3 \mathrm{~Hz}, 2 \mathrm{H}), 2,66-2.56(\mathrm{~m}, 1 \mathrm{H})$ and 2.50 (dt, $J$ 3.0, $12.0 \mathrm{~Hz}, 1 \mathrm{H}), 2.01-1.86(\mathrm{~m}, 5 \mathrm{H})$, 1.79-1.42 (m, 13H), 1.13 (dq, $J 4.1,12.6 \mathrm{~Hz}, 2 \mathrm{H}) .{ }^{13} \mathrm{C} \mathrm{NMR}\left(\mathrm{CDCl}_{3}, 75 \mathrm{MHz}\right): \delta$ 147.5, 147.2, 128.4 (4), 127.0 (2), 126.9 (2), 126.0, 125.9, 68.8, 64.5, 44.6, 43.4, 40.2, 36.0, 33.8 (2), 29.9 (2), 29.2 (2), 26.9 (2). IR: $v_{\max }$ 3500-3000, 2919, 2853, 1724, 1492, 1448, 1274, 1031, 754, 697. HRMS (EI): $m / z$ calcd. for [M] ${ }^{+} \mathrm{C}_{13} \mathrm{H}_{18} \mathrm{O}: 190.13522$, found: 190.13542 .

\section{Acknowledgements}

We thank the Swiss National Science Foundation (grant 20020_135087) and the University of Bern for financial support. We are also grateful to BASF Corporation for generous gift of boron reagents.

\section{References}

1. Radicals in Organic Synthesis, Renaud, P.; Sibi, M.P. Eds.; Wiley-VCH: Weinheim, 2001.

2. Ollivier, C.; Renaud, P. Chem. Rev. 2001, 101, 3415-3434. http://www.dx.doi.org/10.1021/cr010001p

3. Renaud, P.; Beauseigneur, A.; Brecht-Forster, A.; Becattini, B.; Darmency, V.; Kandhasamy, S.; Montermini, F.; Ollivier, C.; Panchaud, P.; Pozzi, D.; Scanlan, E.M.; Schaffner, A.-P.; Weber, V. Pure Appl. Chem. 2007, 79, 223-233. http://www.dx.doi.org/10.1351/pac200779020223

4. Davies, A.G.; Roberts, B.P. Acc. Chem. Res. 1972, 5, 387-392. http://www.dx.doi.org/10.1021/ar50059a005

5. Schaffner, A.-P. ; Renaud, P. Eur. J. Org. Chem. 2004, 2291-2298. http://www.dx.doi.org/10.1002/ejoc.200400131

6. Renaud, P. In Encyclopedia of Radicals in Chemistry, Biology and Materials, Vol. 2 (Synthetic Strategies and Applications; Chatgilialoglu, C.; Studer, A. Eds.; John Wiley \& Sons, Ltd, Chichester, UK, 2012 pp 601-629.

7. Darmency, V.; Renaud, P. Top. Curr. Chem. 2006, 263, 71-106. http://www.dx.doi.org/10.1007/128_030

8. Schaffner, A.-P.; Renaud, P. Angew. Chem. Int. Ed. 2003, 42, 2658-2660. http://www.dx.doi.org/10.1002/anie.200351171

9. Carra, C.; Scaiano, J.C. Eur. J. Org. Chem. 2008, 4454-4459. http://www.dx.doi.org/10.1002/ejoc.200800187

10. Thanthiriwatte, K.S.; Gwaltney, S.R. J. Phys. Chem. A 2006, 110, 2434-2439. http://www.dx.doi.org/10.1021/jp0545492

11. Köster, R.; Benedikt, G. Angew. Chem. 1963, 75, 419-419. 
http://www.dx.doi.org/10.1002/ange.19630750909

12. Köster, R.; Willemsen, H.-G. Liebigs Ann. Chem. 1974, 1843-1850.

http://www.dx.doi.org/10.1002/jlac.197419741114

13. Narula, C.K.; Nöth, H. J. Organomet. Chem. 1985, 281, 131-134.

http://dx.doi.org/10.1016/0022-328X(85)87101-1

14. Hong, H.; Chung, T.C. J. Organomet. Chem. 2004, 689, 58-64.

http://dx.doi.org/10.1016/j.jorganchem.2003.09.027

15. Biswas, S.; Oppel, I.M.; Bettinger, H.F. Inorg. Chem. 2010, 49, 4499-4506.

http://www.dx.doi.org/10.1021/ic902436s

16. Hübner, A.; Qu, Z.-W. ; Englert, U. ; Bolte, M.; Lerner, H.-W.; Holthausen, M.C.; Wagner, M. J. Am. Chem. Soc. 2011, 133, 4596-4609.

http://www.dx.doi.org/10.1021/ja110947k

17. Hübner, A.; Diefenbach, M.; Bolte, M.; Lerner, H.-W.; Holthausen, M.C.; Wagner, M. Angew. Chem. Int. Ed. 2012, 51, 12514-12518.

http://www.dx.doi.org/10.1002/anie.201207335

18. Das, A.; Hübner, A.; Weber, M.; Bolte, M.; Lerner, H-W.; Wagner, M. Chem. Commun. 2011, 47, 11339-11341.

http://www.dx.doi.org/10.1039/C1CC14888E

19. Wehmschulte, R.J.; Diaz, A.A.; Khan, M.A. Organometallics, 2003, 22, 83-92. http://www.dx.doi.org/10.1021/om020611v

20. Grigsby, W.J.; Power, P.P. J. Am. Chem. Soc. 1996, 118, 7981-7988. http://www.dx.doi.org/10.1021/ja960918j

21. Chase, P.A. ; Piers, W.E. ; Patrick, B.O. J. Am. Chem. Soc. 2000, 122, 12911-12912. http://www.dx.doi.org/10.1021/ja005607u

22. Chung, T.-C. U.S. Patent 0091211 A1, 2002.

23. Schaffner, A.-P. ; Darmency, V.; Renaud, P. Angew. Chem. Int. Ed. 2006, 45, 5847-5849. http://www.dx.doi.org/10.1002/anie.200601206

24. Schaffner, A.-P. ; Montermini, F.; Pozzi, D.; Darmency, V.; Scanlan, E.M.; Renaud, P. Adv. Synth. Catal. 2008, 350, 1163-1167.

http://www.dx.doi.org/10.1002/adsc.200700531

25. Bonnafoux, L.; Leroux F.R. ; Colobert, F. Beilstein J. Org. Chem. 2011, 7, 1278-1287. http://www.dx.doi.org/10.3762/bjoc.7.148

26. Ollivier, C.; Renaud, P. Angew. Chem. Int. Ed. 2000, 39, 925-928. http://www.dx.doi.org/10.1002/(SICI)1521-3773(20000303)39:5<925::AIDANIE925>3.0.CO;2-M

27. Dougherty, T.K. ; Lau, K. S. Y.; Hedberg, F.L. J. Org. Chem. 1983, 48, 5273-5280. http://www.dx.doi.org/10.1021/jo00174a023

28. Cheng, J.-H.; Ramesh, C.; Kao, H.-L.; Wang, Y.-J.; Chan, C.-C.; Lee, C.-F. J. Org. Chem. 2012, 77, 10369-10374.

http://www.dx.doi.org/10.1021/jo302088t 
29. Occasionally, for some apolar compounds, the $[\mathrm{M}]^{+}$ion is detected using ESI mode. In such cases, the expected $[\mathrm{M}+\mathrm{H}]^{+}$ion is not present.

30. Paquette, L.A.; Klobucar, W.D.; Snow, R.A. Synth. Commun. 1976, 6, 575-581. http://www.dx.doi.org/10.1080/00397917608063551

31. Lüthy, M.; Darmency, V.; Renaud, P. Eur. J. Org. Chem. 2011, 547-552.

http://www.dx.doi.org/10.1002/ejoc.201001120 